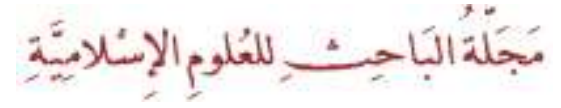

Researcher Journal For Islamic Sciences

Published by the College of Islamic Sciences at the University of Fallujah

ISSN p.p:2708-3993 / ISSN o.l: 2708-4000

Vol;1- Issue;1/ (2020-2021)

\title{
Repentance between Islam and Christianity
}

\author{
Dr. Talal Ahmed Abdullah Al-Jumaili/ The Sunni Endowment Office \\ - Fallujah/talal.aljmely@gmail.com/07814447636
}

Abstract: Summary Study Summary Of No More Than 250 Words Study Summary Of No More Than 250 Words Study Summary Of No More Than 250 Words Study Summary Of No More Than 250 Words Study Summary Of No More This research talks about the virtue of repentance in some detail, in Islam and Christianity, with some comparison between them. Repentance is one of the fundamentals of the religion, and a fundamental pillar of Islam, which the Holy Qur'an urged in many verses, and the Prophet, peace and blessings be upon him, explained the merit of repentance in hadiths. There are many, and in Christianity there are many texts in the Bible that emphasize the importance of repentance, and that repentance is one of the Seven Sacraments of the Church. There will be talk about repentance in Islam, followed by a demand for repentance, confession and forgiveness in Christianity, asking the Almighty God to bless us with forgiveness and satisfaction, and to make this work pure for His honorable sake, and to benefit his readers and Muslims, and praise be to God, Lord of the Worlds.

Keywords: (Bible, Holy Quran, Repentance, New Testament Old Testament). 


\section{التوبة بين الإسلام والمسيحية}

| talal.aljmely@gmail.com الدكتور طلال أحمد عبد الله الجميلي/ ديوان الوقف السني - الفلوجة/ - VAI $\varepsilon \varepsilon \varepsilon \vee \neg 4$

الملتخص:

يتناول هذا البحث فضيلة التوبة بشيء من التفصيل، في الإسلام والمسيحية، مع شيء من المقارنة بينهما، فالتوبة قد حث علئ آليها

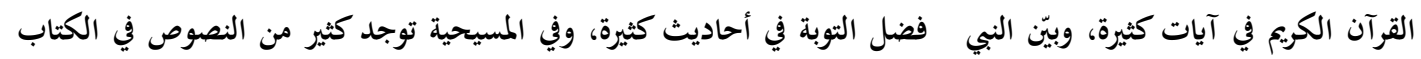

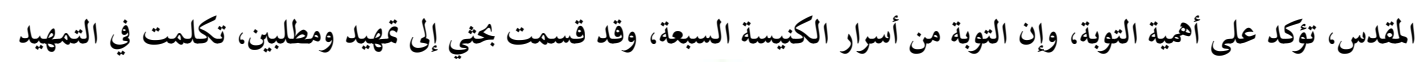

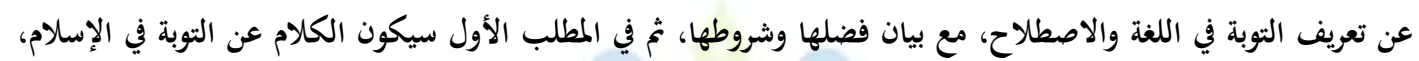

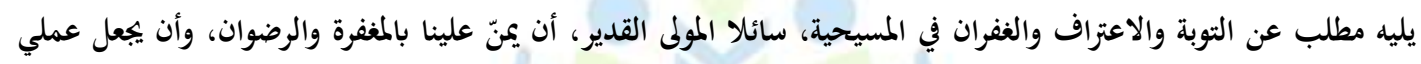

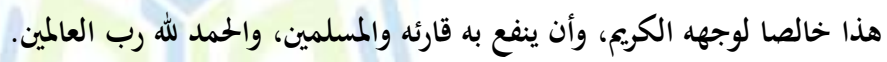
الكلمات المفتاحية: (التوبة، القرآن الكريم، الكتاب المقدس، العهد القديم، العهد الجلديد). 


\title{
التوبة بين الإسلام والمسيحية
}

\author{
الدكتور طلال أحمد عبد الله الجميلي \\ ديوان الوقف السني - الفلوجة
}

المقدمة

الحمد لله الواحد الأحد، والصلاة والسلام على نبيه الكريم أحمد، الذي بشر به عيسى قومه وبجد، وعلى ملى آله وصحبه وتابعيهم بإحسان إلى يوم الدين، وبعد: الداحد، والصناة والدامعل

فإن دراسة علم مقارنة الأديان من أجمل الدراسات وأصعبها في الوقت نفسه؛ كون المتخصص في هذا

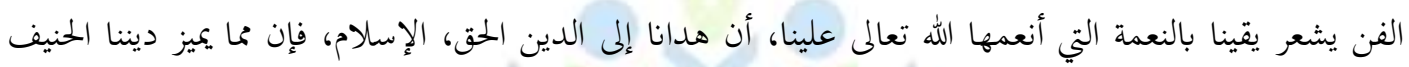

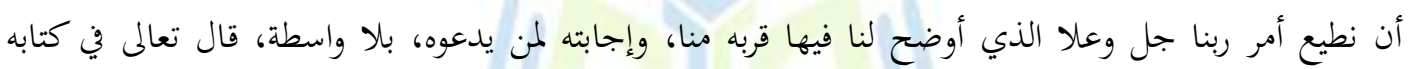

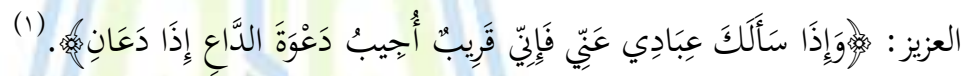
وفي هذا البحث سيتم الكالام عن التوبة بشيء من التفصيل، في الإسلام والمسيحية، مستهلا البحث

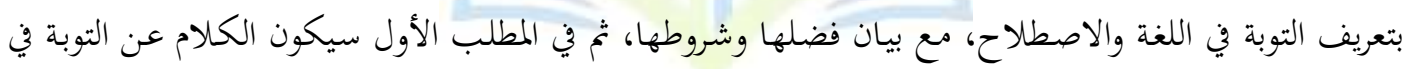

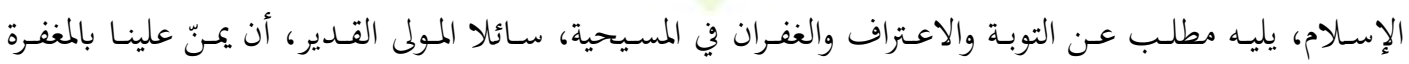

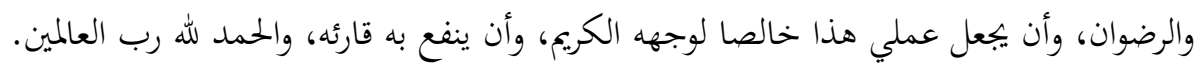

09 . 


\section{تمهيد في تعريف التوبة}

أولاً تعريف التوبة في اللغة: التوبة مصدر الفعل تاب، وأصل هذه المادة: التاء، والواو، والباء توب. وهي

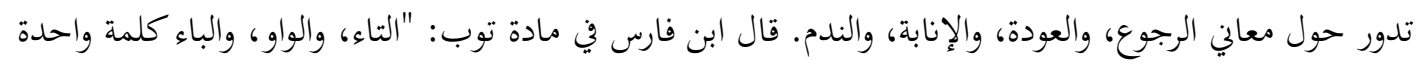

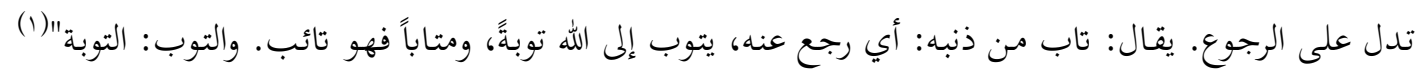
قال الله تعالى: $\}$ غَافِرِ النَّنْبِ وَقَابِلِ التَّوبِ

وقال ابن منظور: "تاب إلى الله يتوب توباً، وتوبة، ومتاباً: أناب، ورجع عن المعصية إلى الطاعة". (r) والتوبة تكون من الله على العبد، ومن العبد إلى الله؛ فإذا كانت من الله عُدِّيت ب(على) وإذا كانت من

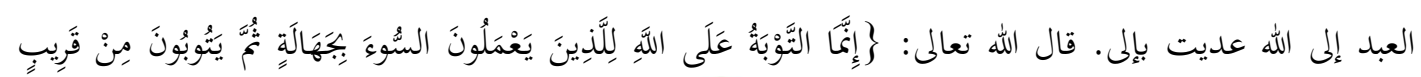

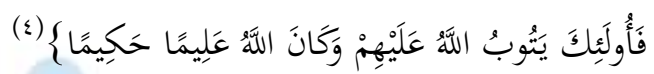

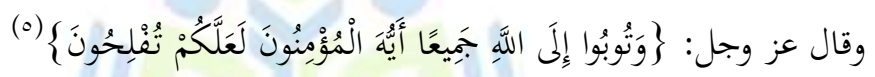

وقال: قال ابن منظور: "وتاب الله عليه: وفقه لما، ورجل تواب: تائب إلى الله، والله تواب: يتوب على عبده...

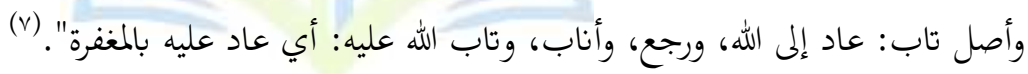
ثانياً تعريف التوبة في الاصطلاح: عرفت التوبة إلى الله في الشرع بعدة تعريفات، والمدلول الشرعي للتوبة قريب من المدلول اللغوي، فمما عرفت به التوبة في الشرع ما يلي:

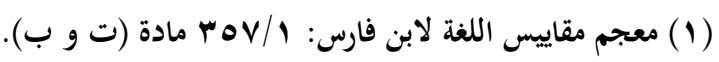

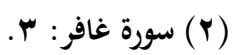

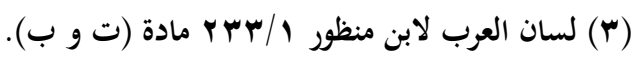

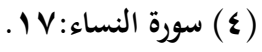

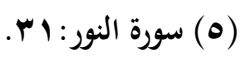

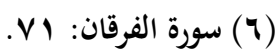

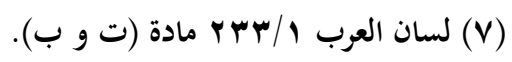


1 ـ قال أبو حامد الغزالي: قيل في حد التوبة أنه ذوبان الحشا لما سبق من الخطأ. (')

r. الندم على معصية من حيث هي معصية، مع عزم أن لا يعود إليها إذا قدر عليها. (r)

r. وباعتبار معنى الترك قيل في حد التوبة: إنه خلع لباس الجفاء، ونشر بساط الوفاء. (r)

ع. ترك المعاصي في الحال، والعزم على تركها في الاستقبال، وتدارك ما سبق من التقصير في سابق الأحوال. (؛) ه. ـ وقال ابن القيم في تعريف التوبة: "حقيقة التوبة هي الندم على ما سلف منه في الماضي، والإقلاع عنه في

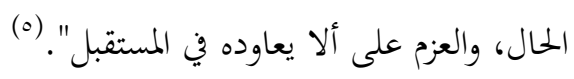

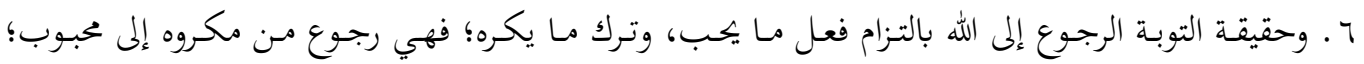

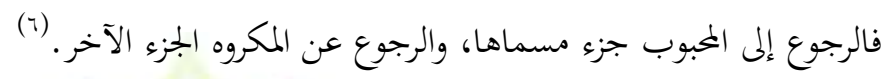

V. وقال: التوبة هي الرجوع مما يكرهه الله ظاهراً وباطناً إلى ما يجبه ظاهراً وباطناً. (v)

م. وقال ابن حجر: والتوبة ترك الذنب على أحد الأوجه، وفي الشرع: ترك الذنب؛ لقبحه، والندم على فعله،

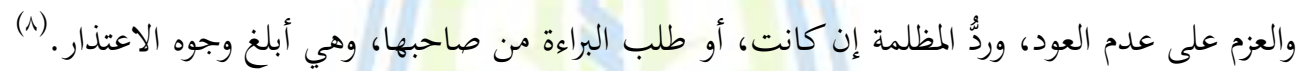

والذي أختاره في تعريف التوبة بأها: ترك الذنب علماً بقبحه، وندماً على فعله، وعزماً على ألا يعود إليه

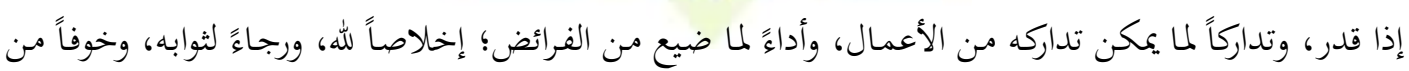
عقابه، وأن يكون ذلك قبل الغرغرة، وقبل طلوع الشمس من مغربها.

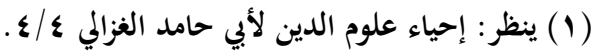

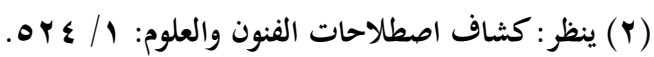

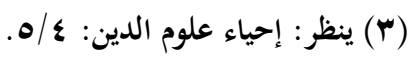

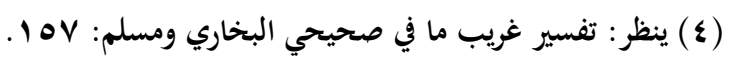

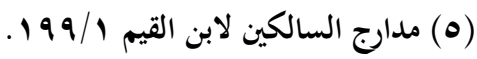

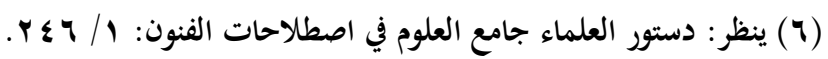

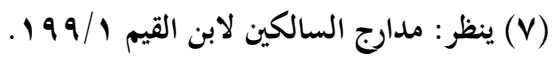

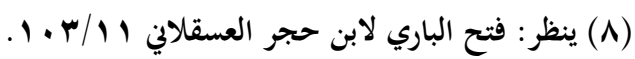




$$
\text { أولا: شروطها }
$$

من خلال ما سبق يتبين لنا أن التوبة لابد أن يجتمع فيها الشروط التالية:

$$
\text { 1 الإقلاع عن الذنب. }
$$

r. الندم على ما فات، والحد الأدنى من ذلك وجود أصل الندم، وأما قوة الندم وضعفه فبحسب قوة التوبة، وضعفها.

$$
\text { ع. ــ العلم بقبح الذنب. }
$$

ه. تدارك ما يمكن تداركه من رد المظالم ونو ذلك

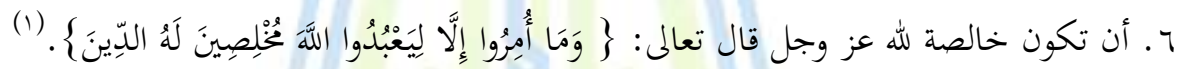

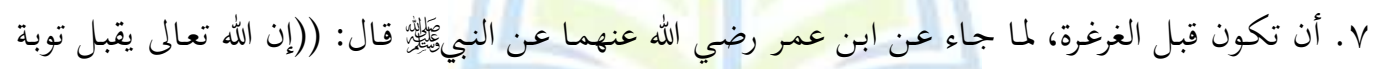

$$
\text { العبد ما لم يغرغر)(ا). (r) (ان تكون فيل الغرغر }
$$

والغرغرة هي حشرجة الروح في الصدر، والمراد بذلك الاحتضار عندما يرى الملائكة، ويبدأ به السياق في

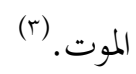

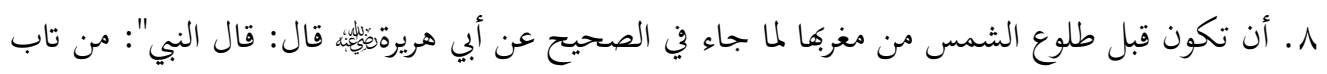

०9T

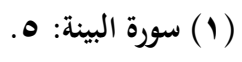

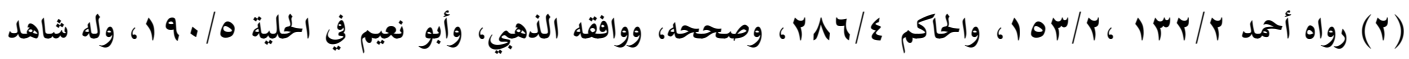

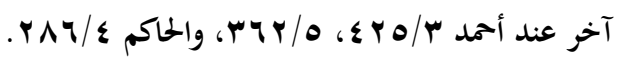

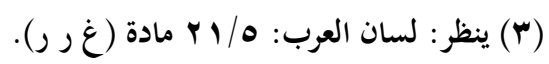


قبل أن تطلع الشمس من مغربها تاب الله عليه. (1)

$$
\text { ثانيا: فضل الله عز وجل في فتح باب التوبة. }
$$

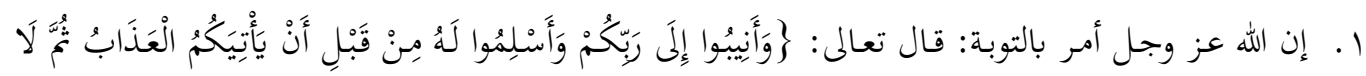

$$
\text { (r) }
$$

قال ابن كثير في تفسير هذه الآية: أي ارجعوا إلى الله، واستسلموا له من قبل أن يأتيكم العذاب ثم لا

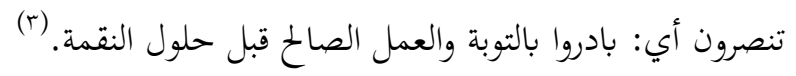

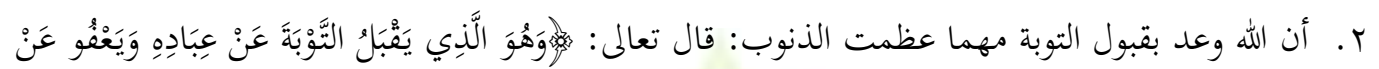

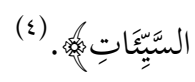

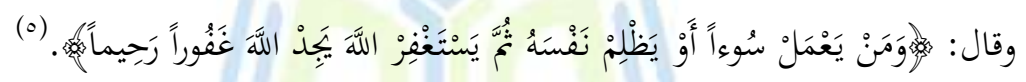

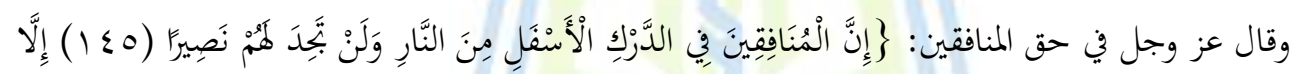

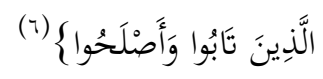

وقال تعالى في حق أصحاب الأخدود الذين خدوا الأخاديد لتعذيب المؤمنين وتحريقهم بالنار:

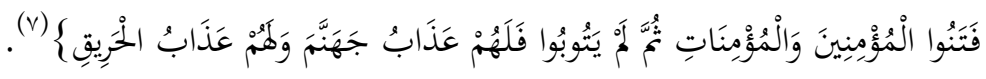

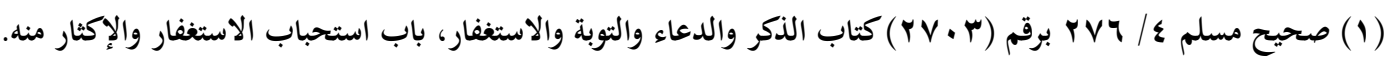

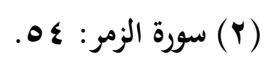

$$
\text { T Y T) }
$$

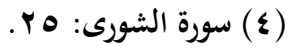

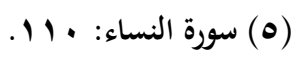

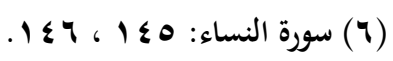

(V) سورة البروج: .

095 
ورد عن بعض السلف الصالح أنه ذكر هذه الآية الكريمة، وبيّن أن فيها مسألة لطيفة، وهي أن باب التوبة

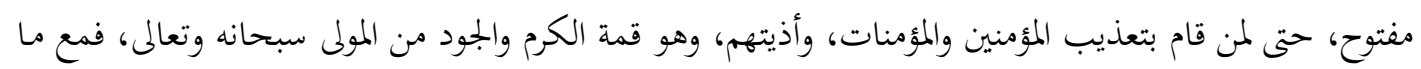

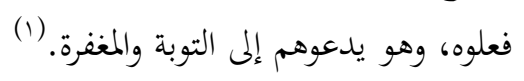

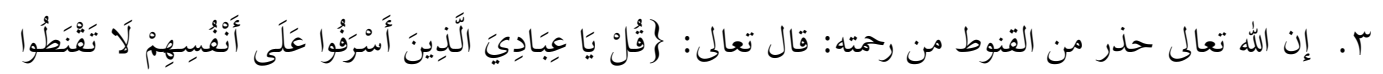

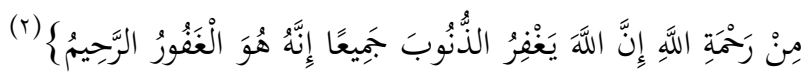

ثمَ دعا إلى التوبة من هو أعظم قولاً مسن هؤلاء؛ مـن قال:

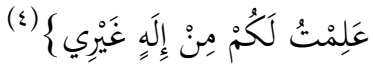

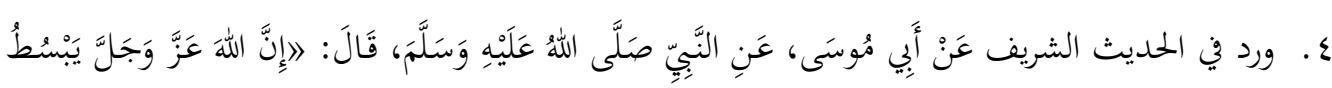

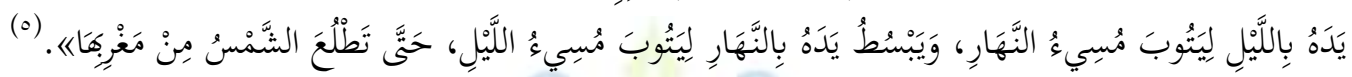
هـ ـ أن الله رتب الثواب الجزيل على التوبة: ووعد من تاب بالخير الكثير، وهذا ما سيتبين في المبحث الآتي إن شاء الله تعالى. ثالثا: فضائل التوبة

للتوبة فضائل جمة، وأسرار بديعة، وفوائد متعددة، فمن ذلك ما يلي:(1) ا. التوبة سبب للفلاح: قال تعالى:

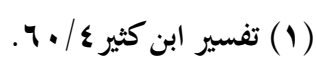

$$
\begin{aligned}
& \text { (Y) سورة الزمر : به (1) }
\end{aligned}
$$

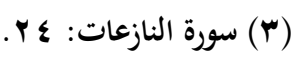

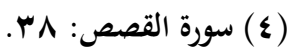

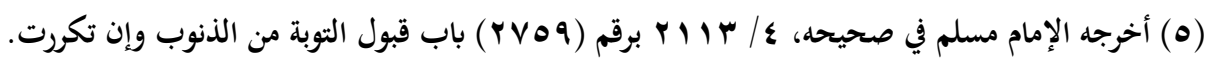

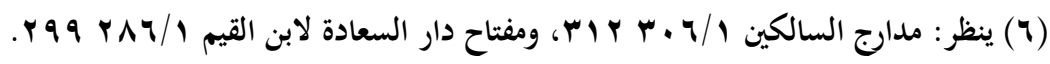

$$
\begin{aligned}
& \text { سورة النور: آس. }
\end{aligned}
$$

090 
وقال ابن كثير: أي افعلوا ما آمركم به من هذه الصفات الجميلة والأخلاق الجليلة، واتركوا ما كان عليه

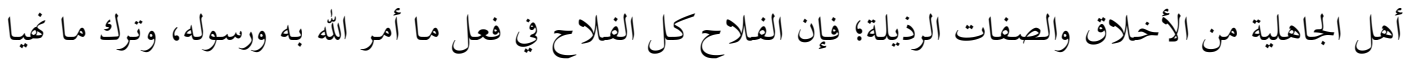
(r) عنه.

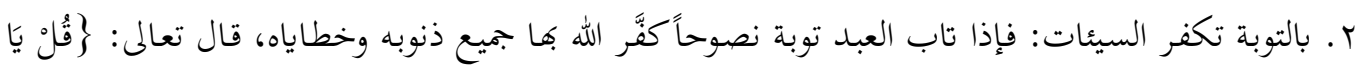

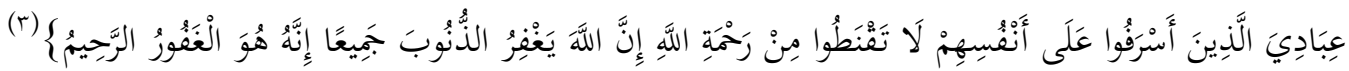

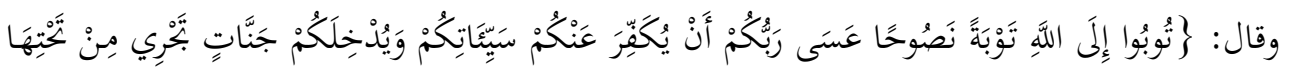

(๕)

r. بالتوبة تبدل السيئات حسنات: فإذا حسنت التوبة بدَّل الله سيئات صاحبها حسنات، وذلك فضل

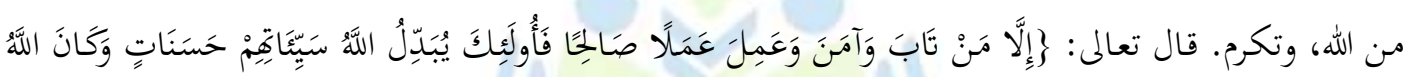
غَفْورًا رَحِيمًا قال ابن القيم في هذه الآية: وهذا من أعظم البشارة للتائبين إذا اقترن بتوبتهم إيمان وعمل صالح، وهو

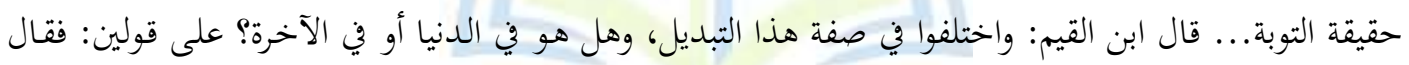

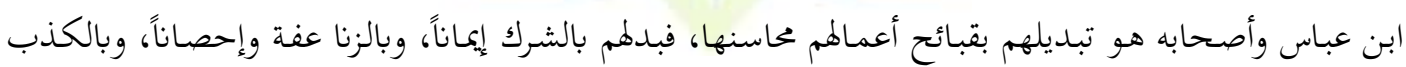

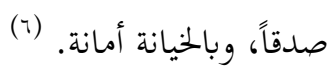

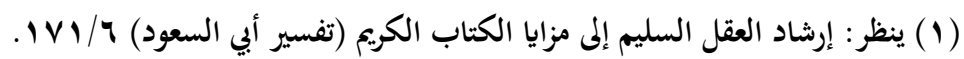

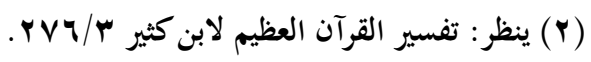

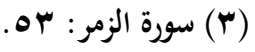

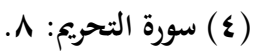

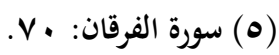

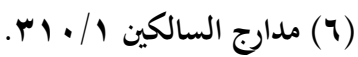




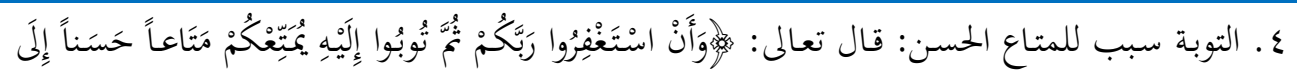

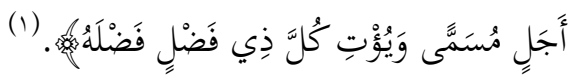

هـ التوبة سبب لنزول الأمطار، وزيادة القوة، والإمداد بالأموال والبنين: قال تعالى على لسان هود عليه

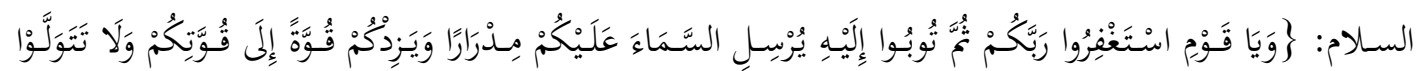
(r)

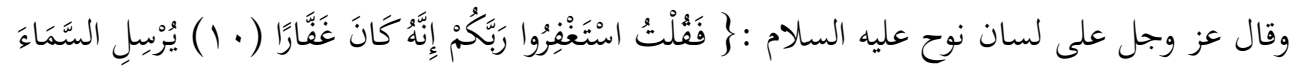

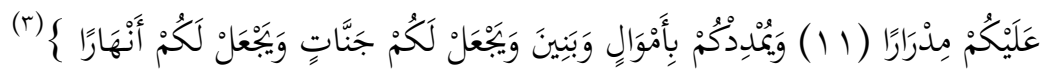
آ. أن الله يحب التوبة والتوابين: فعبودية التوبة من أحب العبوديات إلى الله وأكرمها؛ فإنه سبحانه يحب

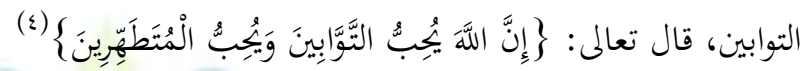

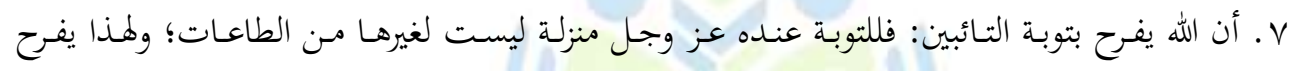

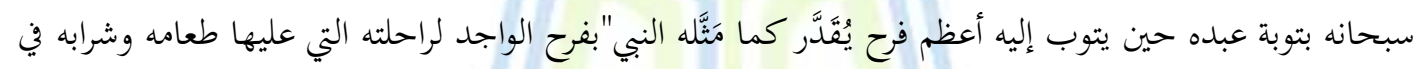

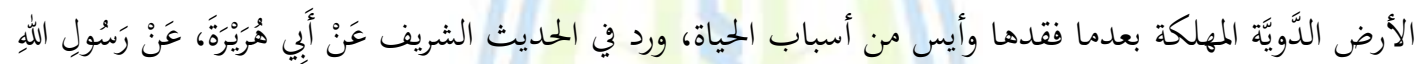

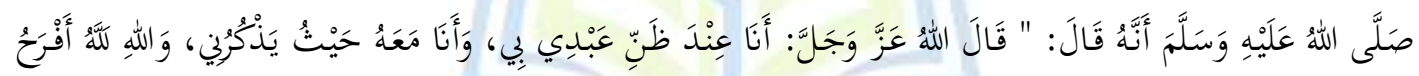

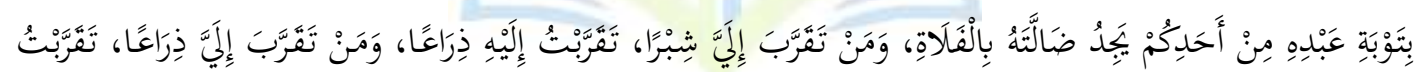

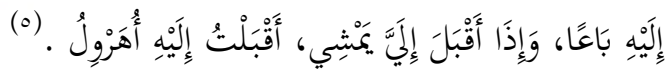

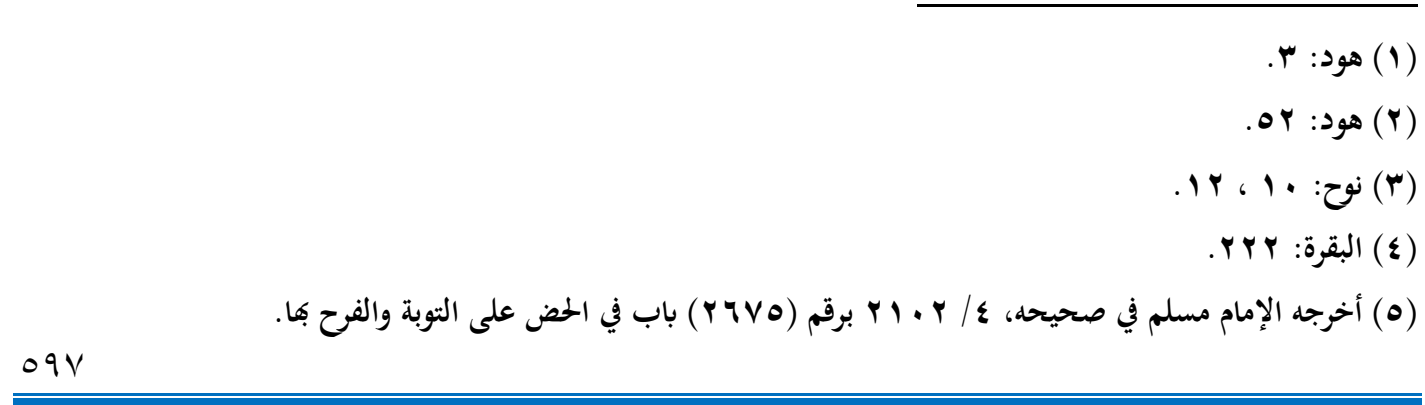




\section{المطلب الثالي: التوبة في المسيحية}

في الديانة المسيحية، تتمثل التوبة بركنين أساسيين هما: الندم، والاعتراف إلى القس في الكنيسة، وهذان الأمران كفيلان بمسح الذنب وعدم بقاء آثاره، جاء في الكتاب المقدس: "لا تستحي أن تعترف بخطاياك، ولا

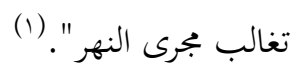

حيث يرون في عقيدقم أن الرب تعالى قد أمر الإنسان أن يعترف بخطاياه للقس في الكنيسة، وأن لا يقف في وجه تيار مجرى النهر، وهو كناية عن قوة عدم الانجرار وراء الشهوات والملذات، والاعتراف بالتقصير والذنب.

يقول أحد الكرادلة: "يُخبِبنا الإنجيل عن مغفرة يسوع لأناس عديدين. والمغفرة تعني أن يصالح الإنسان

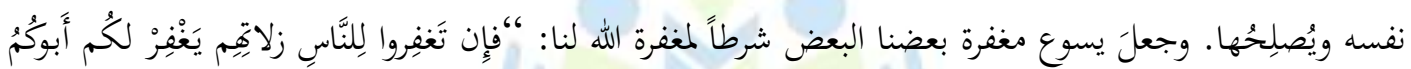

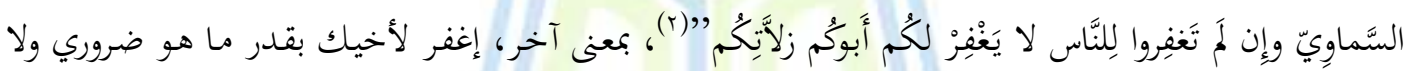

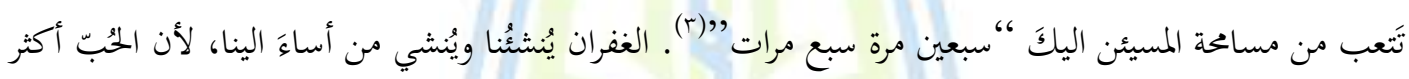

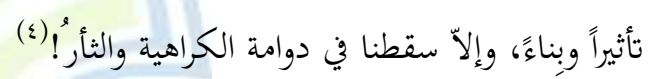
والمعروف في الديانة المسيحية أن التوبة والاعتراف والغفران هي من خصائص الكاثوليك والأرثوذوكس فقط، أما الكنيسة البروتستانتية (الإنجيلية) فهي لا تعترف بصكوك الغفران ولا بالاعتراف الذي هو من أسرار الكنيسة السبعة، التي يؤمن بها أفراد الطوائف المسيحية الأخرى.

$$
\begin{aligned}
& \text { (1) سفر يشوع بن سيراخ ؛ : اس (1) } \\
& \text { (Y) }
\end{aligned}
$$

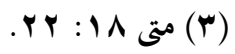

(؟) مقال بعنوان (سرّ المصالحة (الاعتراف) التوبة والغفران) للكاردينال لويس روفائيل ساكو، منشور على موقع (أبونا) على (بانى 091

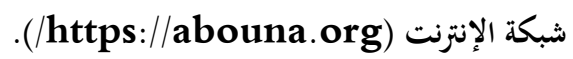


ويقول أحد القديسين" (1) “لايقولنَّ أحُد، عندما لا أحبّ أخي فأنا اخطئ ضد إنسان، ولكن كيف لاتخطئ ضد الله عندما تخطئ ضد الحب". كيف نقدر أن نعود الى البيت الأبوي من دون مصالحة إخوتنا؟ السرّ لا يكون صحيحاً من دون الغفران والمصالحة. ولتحديد مسؤولية الخاطئ لابد أن تتوفر لديه المعرفة والإرادة الحُرّة. الخطايا الجسيمة تحتـاج الى سرّ التوبة (الإعتراف) ويشـد الكتاب المقدس على ترك المعاصي والخطايا والآثام، وتطهير النفس من آثارها السلبية، وذكر في كثير من الإصحاحات أهمية التوبة قبل الموت، عن طريق الاعتراف في الكنيسة، إذ أن للكنيسة أسرارا سبعة، تختص بها، ولا يصح من المؤمن أن يعملها خارجها، أهمها التوبة والاعتراف، جاء في سفر يشوع: "جعل للتائبين مرجعًا، وعزَّى ضعفاء الصبر، ورسم لهم نصيب الحق. فَتُب إلى الرب، واقلع

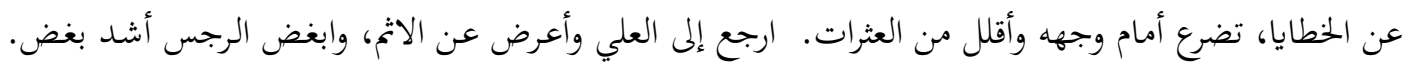
فهل من حامد للعلي في الجحيم؟! تعلم أوامر الله وأحكامه، ادخل في ميراث الدهر المقدس مع الأحياء المعترفين

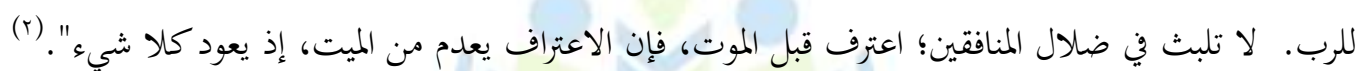
ومـن الجـدير بالذكر أن التوبة في الأمم السابقة للمسيحية، كانت مشـروطة بتقديم القرابين، وهي مـن العبادات المقدسة، فكان تقديم القربان من أمور الشريعة وصنوف العبادات، وكانت له طقوس خاصة، ونتائج يلمسها المرء، فكان من يتقرب إلى الله تعلى بقربان ما، يعرف بعد مدة وجيزة ما إذا كان قربانه متقبلا أم لا، فقد

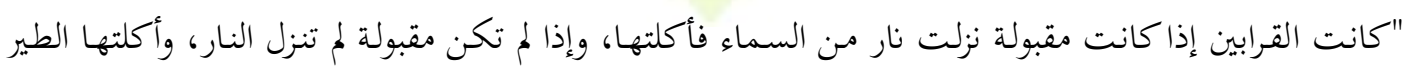


أو كان "يقرب المقرب قربانه ويقوم يصلي ويسجد، فإن نزلت نار وأكلت القربان فذلك دليل للقبول وإلا

$$
\text { كان تركه دليل عدم القبول". (1) }
$$

أما كيفية تقديم القرابين، فقد ورد في الكتاب المقدس الشروط الآتية:

$$
\begin{aligned}
& \text { ( ) وضع اليد على الرأس.) } \\
& \text { (r) الاعتراف بالخطيئة. }
\end{aligned}
$$

r) قيام المضحي بذبح قربانه بنفسه، هو أو الكاهن. (๕)

ع) قيام المضحي بسلخ أضحيته بنفسه، وإن لم يستطع يقوم اللاويون بالمساعدة. (o)

$$
\text { ( ) ) ) رقطيع الذبيحة. }
$$

وعودا على الاعتراف والتوبة في المسيحية، فالباحث في الكتاب المقدس يرى كثيرا من أسفاره وإصحاحاته

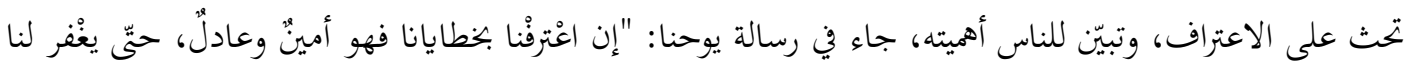

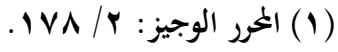

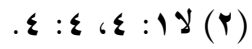

$$
\begin{aligned}
& \text { (צ) } \\
& \text { (צ) } \\
& \text { (8) } \\
& \text { (7) لا }
\end{aligned}
$$

7.. 


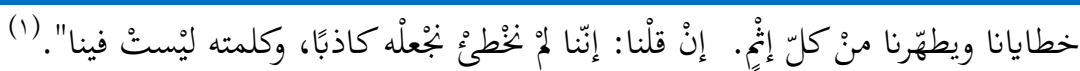

ومن الجدير بالذكر أن الكتاب المقدس لدى المسيحيين يتكون من قسمين: العهد القديم والعهد الجديد،

وإن العهد القديم قد اشتمل على بعض النصوص التي تحث على التوبة والاعتراف أيضا، منها ما جاء في سفر

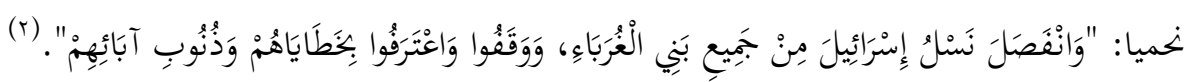
ففي هذا النص يبين السفر قصة بني إسرائيل، وكيف أفم تابوا إلى الله تعالى بالاعتراف بخطاياهم وذنوبهم، وكذلك ذنوب آبائهم.

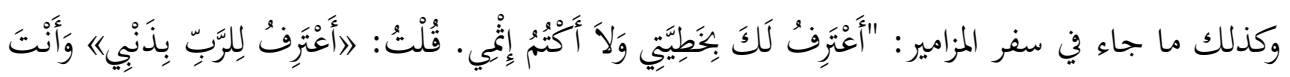

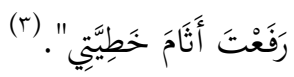

والتوبة الحقيقية في المسيحية لا بـد أن تكون توبة مثمرة، قال يوحنـا المعمـدان لمن جـاء إلى معموديته

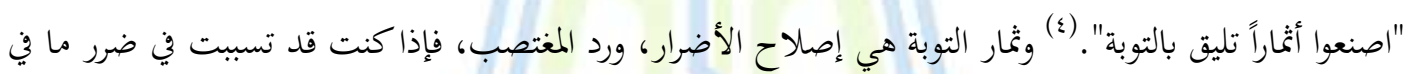

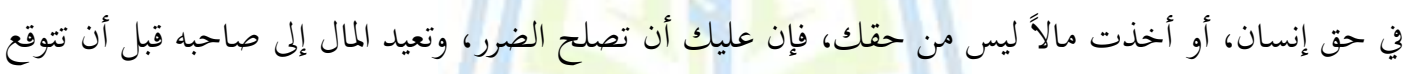
غفران الله. فكم من أناس يعيشون في حالة اليأس، يحيط بهم الظالام لأفم لا يريدون أن يعترفوا بخطاياهم ويتوبوا

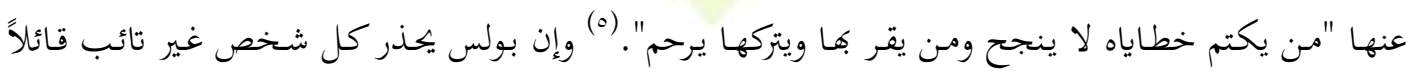
والكلام هنا عن الله: "أم تستهين بغنى لطفه وإمهاله وطول أناته غير عالم أن لطف الله إنما يقتادك إلى التوبة.

$$
\begin{aligned}
& \text { (1) رسالة يوحنا الرسول الأولى 1: 9، · 1. } \\
& \text { (Y) سفر نحميا 9: Y) }
\end{aligned}
$$

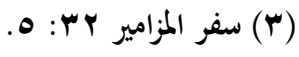

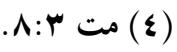

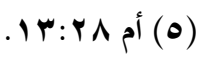

7.1 
ولكنك من أجل قساوتك وقلبك غير التائب تذخر لنفسك غضباً في يوم الغضب واستعلان دينونة الله

(1) العادلة" (

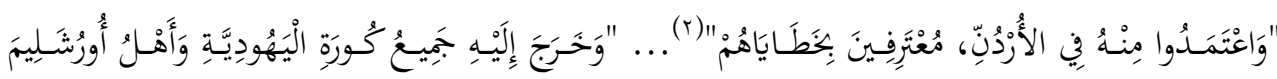

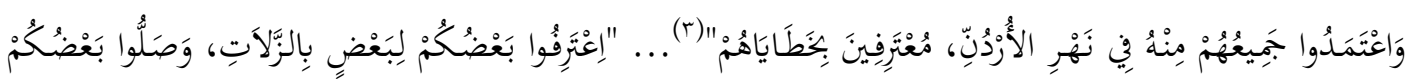

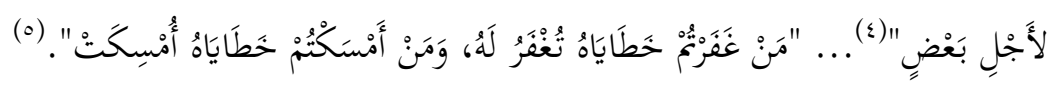

وإلى غيرها من النصوص الكثيرة التي تحث على سر الاعتراف والغفران، الذي هو من خصائص الكنيسة

$$
\text { الغربية والشرقية. }
$$

T. $Y$

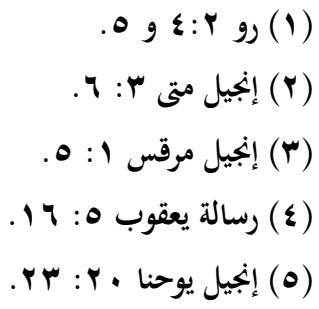




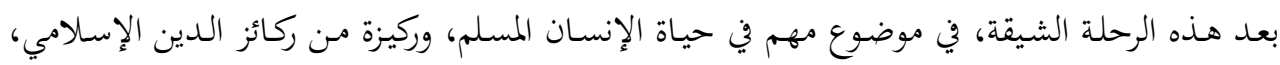

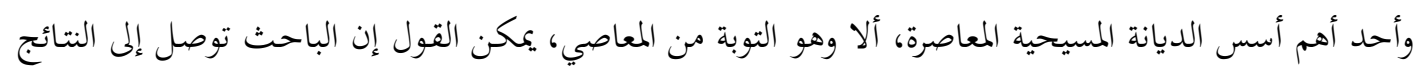
الثالية:

هيث الإسلام في نصوص قرآنية كثيرة، على أهية التوبة قبل فوات الأوان، وقد بين القرآن الكريم فضل التوبة

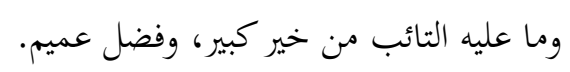

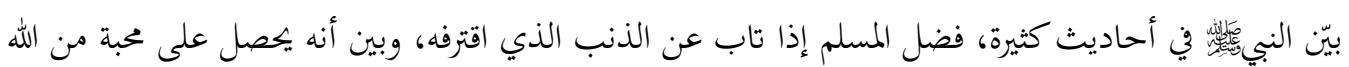
تعالى، فهو جل وعلا يحب التوابين، والتواب صيغة مبالغة من تائب، وهو الذي يذنب كثيرا، ويتوب كثيرا.

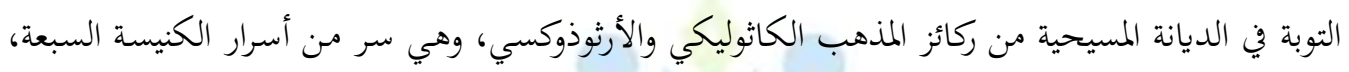
وهي غختصة برجال الدين، فهم وحدهم لديهم الحق في مغفرة الذنوب، بعد أن يعترف المرئ المسيحي بكا.

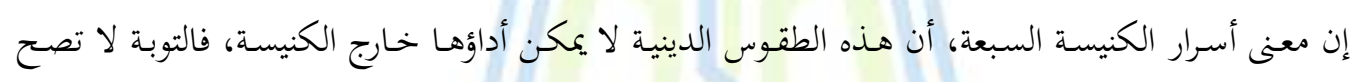

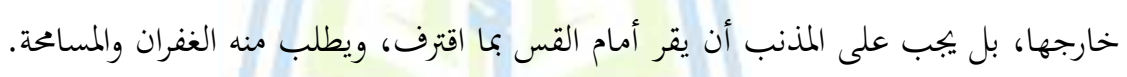

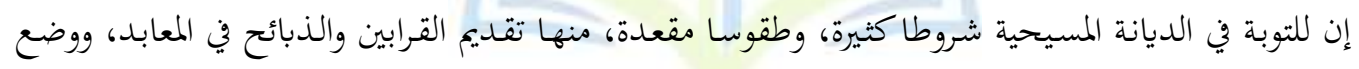
اليد على الرأس وغيرها. 


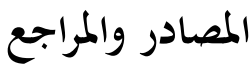

\section{بعد القرآن الكريم}

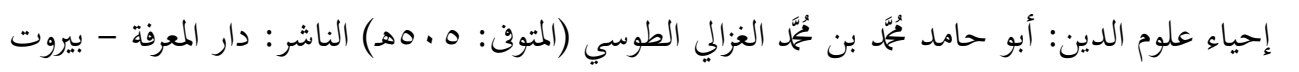

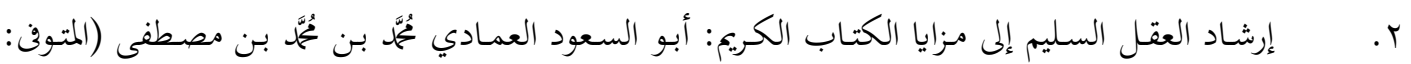

$$
\text { r بهـهـ الناشر: دار إحياء التراث العربي - بيروت }
$$

r. الاستقامة: تقي الدين أبو العباس أحمد بن عبد الحليم بن عبد السلام بن عبد الله بن أبي القاسم بن يُمَّمَ

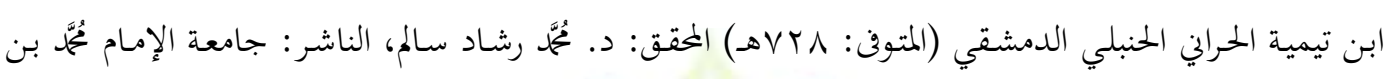

$$
\text { سعود - المدينة المنورة، الطبعة: الأولى، ب.ع إل }
$$

ع. إغاثة اللهفان من مصايد الشيطان: مُحَّة بن أبي بكر بن أيوب بن سعد شمس الدين ابن قيم الجوزية

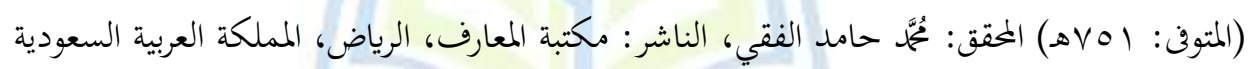

ه. تفسير القرآن العظيم: أبو الفداء إسماعيل بن عمر بن كثير القرشي البصري ثم الدمشقي (المتوفى: عVVهـ) المحقق: سامي بن يُمَّمَ سلامة، الناشر: دار طيبة للنشر والتوزيع، الطبعة: الثانية . بـ اهـ - 999 ام 7. التوبة والاستغفار: لابن تيمية، تحقيق: مُحَّمَ الحجاجي وعبد الله بدران ؟؟؟

V.الجامع الكبير - سنن الترمذي: عُمَّمَ بن عيسى بن سَوْرة بن موسى بن الضحاك، الترمذي، أبو عيسى (المتوف: P TV9) المحقق: بشار عواد معروف، الناشر: دار الغرب الإسلامي - بيروت، 1991 م 


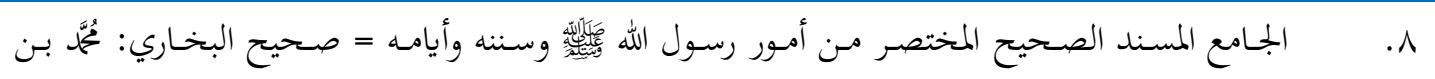
إسماعيل أبو عبدالله البخاري الجعفي، المحقق: يُحَّمَ زهير بن ناصر الناصر، الناشر: دار طوق النجاة (مصورة عن السلطانية بإضافة ترقيم ترقيم مُحمّمَ فؤاد عبد الباقي)، الطبعة: الأولى، ب بع اهـ

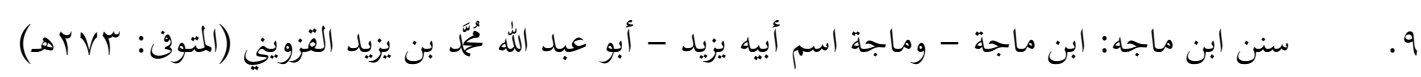
المحقق: شعيب الأرنؤوط - عادل مرشد - محمَّد كامل قره بللي - عَبد اللّطيف حرز الله، الناشر: دار الرسالة

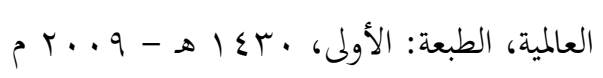
• 1 . صحيح ابن حبان بترتيب ابن بلبان: عُمَّهُ بن حبان بن أحمد بن حبان بن معاذ بن مَعْبَ، التميمي، أبو حاتم، الدارمي، البُستي (المتوف: ـــهـ) المحقق: شعيب الأرنؤوط، الناشر: مؤسسة الرسالة - بيروت، الطبعة: الثانية، عا

11. فتح الباري شرح صحيح البخاري: أحمد بن علي بن حجر أبو الفضل العسقلاني الشافعي، الناشر: دار

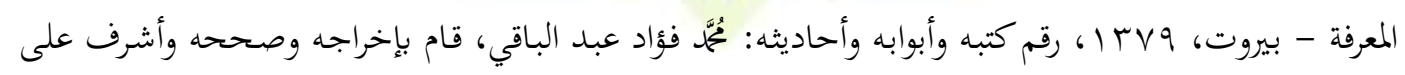
طبعه: محب الدين الخطيب

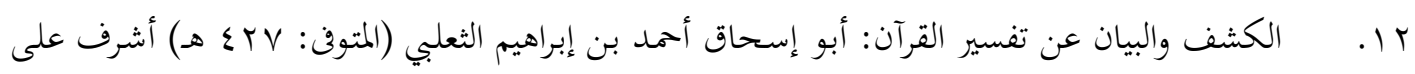
إخراجه: د. صلاح باعثمان، د. حسن الغزالي، أ. د. زيد مهارش، أ. د. أمين باشه، تحقيق: عدد من الباحثين ( اYT) مثبت أسماؤهم بالمقدمة (صـ ه ) الناشر: دار التفسير، جدة - المملكة العربية السعودية، الطبعة: الأولى، 
rا. . لسان العرب: مُحَّمَ بن مكرم بن على، أبو الفضل، جمال الدين ابن منظور الأنصاري الرويفعى الإفريقى

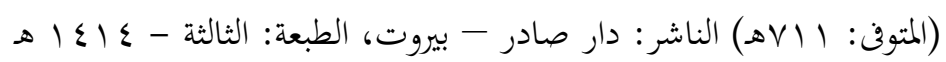

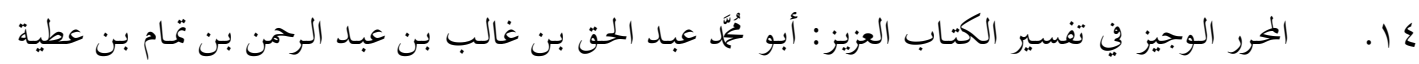

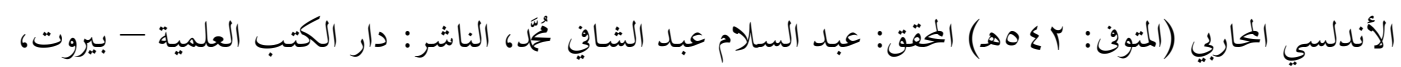

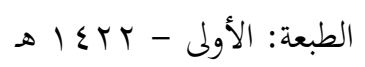

10. مدارج السالكين بين منازل إياك نعبد وإياك نستعين: تُمَّمَ بن أبي بكر بن أيوب بن سعد شمس الدين ابن قيم الجوزية (المتوفن: 101هـ) المحقق: مُحَّمَ المعتصم بالله البغدادي، الناشر: دار الكتاب العربي - بيروت، الطبعة:

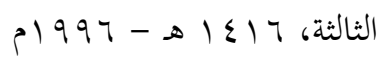

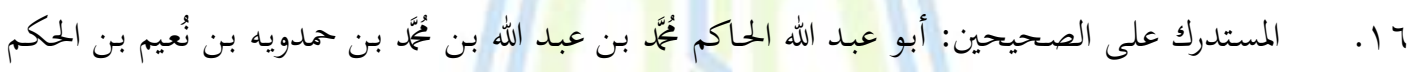
الضبي الطهماني النيسابوري المعروف بابن البيع (المتوف: ه ـ هـ) تحقيق: مصطفى عبد القادر عطا، الناشر: دار

$$
\text { الكتب العلمية - بيروت، الطبعة: الأولى، 11 199 }
$$

V V ا. مسند أبي يعلى: أبو يعلى أحمد بن علي بن المثُنى بن يهيى بن عيسى بن هلال التميمي، الموصلي

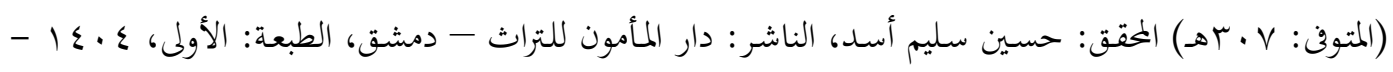

11. مسند الإمام أحمد بن حنبل: أبو عبد الله أحمد بن عُمَّمَ بن حنبل بن هلال بن أسد الشيباني (المتوفى:

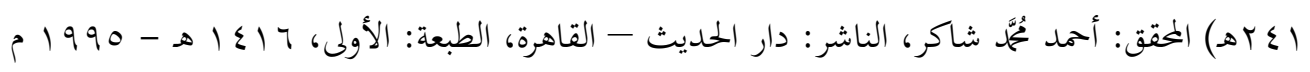




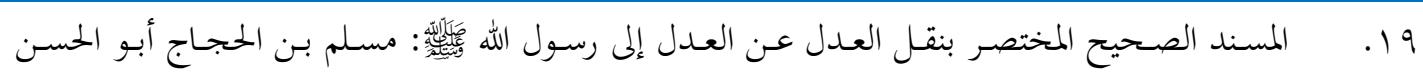
القشيري النيسابوري (المتوف: ابح هـ) المحقق: ثُعَّمَ فؤاد عبد الباقي، الناشر: دار إحياء التراث العربي - بيروت

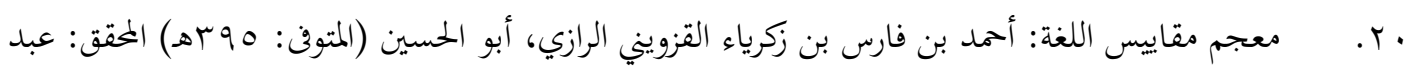

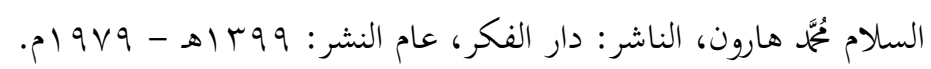

آT. مفتاح دار السعادة ومنشور ولاية العلم والإرادة: أبو عبد الله مُحَّم بن أبي بكر بن أيوب ابن قيم الجوزية

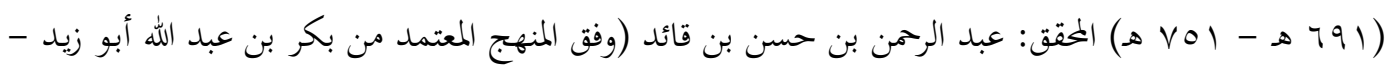
رحمه الله -) راجعه: مُحَمَّدْ أَجمَّل الإصْلاحِي، سليمان بن عبد الله العمير، الناشر : دار عالمُ الفوائد، مكة المكرمة،

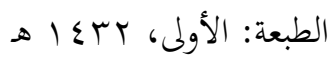

r T. مقال بعنوان (سرّ المصالحة (الاعتراف) التوبة والغفران) للكاردينال لويس روفائيل ساكو، منشور على موقع (أبونا) على شبكة الإنترنت (/https://abouna.org). 